\title{
Nasal High Frequency Oscillatory Ventilation for Respiratory Failure due to Respiratory Syncytial Virus Bronchiolitis: Case Report
}

\author{
Pio Liberatore, MD ${ }^{1}$ Gianfranco Maffei, MD ${ }^{1}$ \\ ${ }^{1}$ Neonatal Intensive Care Unit, Policlinico Riuniti, Foggia, Italy \\ Am J Perinatol Rep 2020;10:e253-e254.
}

\begin{abstract}
Address for correspondence Gianfranco Maffei, MD Neonatal Intensive Care Unit, Policlinico Riuniti, Foggia, Italy (e-mail: gfmaffei@tiscali.it).
\end{abstract}

\author{
Abstract \\ Keywords \\ - nasal high frequency \\ oscillatory ventilation \\ - bronchiolitis \\ - infant
}

The authors describe a case of acute respiratory failure due to severe bronchiolitis. During high-flow nasal cannula ventilation, the blood's high levels of hypercapnia had taken them to plan the sedation and the orotracheal intubation. However, before attempting intubation, a nasal high frequency oscillatory ventilation cycle was performed and it led to a marked improvement in the blood gas, avoiding in this way the invasive ventilation.
Premature infants are a high-risk group for acquiring respiratory syncytial virus (RSV) infection. ${ }^{1}$ The American Academy of Pediatrics guidelines recommend only supportive therapy that includes oxygen therapy for hypoxemia, respiratory support, and hydration. In case of severe bronchiolitis, characterized by hypoxemia, hypercarbia, and increased work of breathing, is recommended tracheal intubation and mechanical ventilation. ${ }^{2}$ The review of literature for respiratory support modalities in infants with bronchiolitis showed that there is increasing evidence to recommend the use of noninvasive respiratory support. In particular, the high-flow nasal cannula (HFNC) has several proven physiological benefits, which include $\mathrm{CO}_{2}$ washout of the anatomical dead space of the upper airway; humidification and heating of the inspired gas; reduced inspiratory work of breathing; and creation of positive end expiratory pressure in the airway. ${ }^{3}$

On the other hand, nasal high frequency oscillatory ventilation (nHFOV) has also high efficacy in removing $\mathrm{CO}_{2}$. Moreover, it delivers a nasal continuous positive airway pressure that increases in functional residual capacity that improves the oxygenation. In this way, nHFOV matches together the advantages of high-frequency ventilation (no need for synchronization) and nasal continuous positive airway pressure (NCPAP) (noninvasive interface). ${ }^{4}$

We report a case of a premature infant with RSV-associated hypoxemic hypercapnic respiratory failure who had failed with usual non-invasive modalities of ventilation (HFNC and noninvasive positive pressure ventilation [NIPPV]) and significant improvement in ventilation with nHFOV.

\section{Case Presentation}

Laura was a 27-day-old girl (3.3 kg). She was born preterm $\left(33^{4 / 7}\right.$ weeks of gestation) by cesarean delivery for twins; no particular risk factors. Last February, she was hospitalized in our neonatal intensive care unit due to frequent sneezing, coughing, and feeding difficulties for approximately 3 days. Total 6 hours earlier, her twin sister was hospitalized for bronchiolitis. Arterial blood gas (ABG) at admission was normal, so we started support only feeding.

In the following hours, she did not need oxygen supplementation neither ventilatory support. RSV test was positive, and CRP resulted $31.8 \mathrm{~mL} / \mathrm{L}$ (normal value $<5 \mathrm{~mL} / \mathrm{l}$ ). Thus, antibiotic therapy was started (clarithromycin).

About 24 hours after admission, because of recurrent desaturations, high-flow nasal cannula (HFNC) ventilation (delivered by Precision Flow Plus Vapotherm) was started with $\mathrm{FiO}_{2} 25 \%$ with a flow of $6 \mathrm{~L} / \mathrm{min}$. ABG after 30 minutes showed: $\mathrm{pH} 7.34, \mathrm{pCO}_{2} 47.2 \mathrm{~mm} \mathrm{Hg}, \mathrm{pO}_{2} 44.9 \mathrm{~mm} \mathrm{Hg}$, and sat $\mathrm{O}_{2} 85 \%$. So, $\mathrm{FiO}_{2}$ was increased to $30 \%$.

Total 8 hours later, for the recurrent desaturations and the worsening of the clinical conditions, a chest X-ray was performed and it showed "right upper lobe atelectasis with lower lobe hyperexpansion; opacification of the left hemithorax, received

May 9, 2020

accepted

June 1,2020
DOI https://doi.org/

10.1055/s-0040-1715179. ISSN 2157-6998.
Copyright $\odot 2020$ by Thieme Medical Publishers, Inc., 333 Seventh Avenue, New York, NY 10001, USA. Tel: +1(212) 760-0888.
License terms

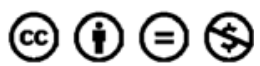


probably due to atelectasis." ABG: pH 7.30, $\mathrm{pCO}_{2} 61.5 \mathrm{~mm} \mathrm{Hg}$, and $\mathrm{pO}_{2} 37.8 \mathrm{~mm} \mathrm{Hg}$. Thus, we decided to start NIPPV setting the following parameters: positive end-expiratory pressure $5 \mathrm{~cm} \mathrm{H}_{2} \mathrm{O}$; peak inspiratory pressure $20 \mathrm{~cm} \mathrm{H}_{2} \mathrm{O}, \mathrm{FiO}_{2} 30 \%$, and a respiratory rate of $40 /$ minute, and then brought to $50 /$ minute. The NIPPV failed because the day after clinical conditions were worsened: she appeared cyanotic with increased work of breathing with very important subdiaphragmatic, intercostal, and jugular retractions; at pulmonary physical examination: high reduction of air intake bilaterally with scattered crackling rales and inspiratory and expiratory wheezing. So, we performed an aerosol with adrenaline and saline solution to improve the work of breathing. ABG performed 30 minutes later showed: $\mathrm{pH} 7.33, \mathrm{pCO}_{2} 60 \mathrm{~mm} \mathrm{Hg}$, $\mathrm{pO}_{2} 43.9 \mathrm{~mm} \mathrm{Hg}$, and saturated $\mathrm{O}_{2} 82 \%$. At this point, to reduce the $\mathrm{pCO}_{2}$ and consequently avoid the intubation, we decided to make an attempt of ventilation with nHFOV. The nHFOV was delivered by BabyLog VN500 (Dräger, Lubeck, Germany) using well-tolerated RAM cannula. Ventilation was started with a mean airway pressure of $12 \mathrm{~cm} \mathrm{H}_{2} \mathrm{O}, \Delta \mathrm{P}$ (peak-to-peak pressure amplitude) increased until visible mouth and neck oscillations, reached at approximately $33 \mathrm{~cm} \mathrm{H}_{2} \mathrm{O}$, and a frequency of $10 \mathrm{~Hz}$ ( $\left.\mathrm{I}: \mathrm{E}=1: 1 ; \mathrm{FiO}_{2} 40 \%\right)$. Total 3 hours later, work of breathing seemed to be improved and the ABG showed: $\mathrm{pH}$ 7.38, $\mathrm{pCO}_{2} 50.6 \mathrm{~mm} \mathrm{Hg}, \mathrm{pO}_{2} 49.8 \mathrm{~mm} \mathrm{Hg}$, and saturated $\mathrm{O}_{2}$ $89.4 \%$.

The day after, clinical conditions were slightly improved: work of breathing further reduced and saturation increased. She continued nHFOV for 1 day more until the $\mathrm{pCO}_{2}$ reached $41.1 \mathrm{~mm} \mathrm{Hg}$. At this point, we went back to HFNC for 2 days and then we stop the ventilation.

\section{Conclusion}

The use of nHFOV in the respiratory failure due to RSV bronchiolitis has never been previously described in any case report in the scientific literature. We know that nHFOV, as like NCPAP, keeps the lung open and maintains functional residual capacity. Additionally, it adds extremely fast oscillations of very small tidal volume less than the dead space to the continuous pressure that supports the ventilation and removal of $\mathrm{CO}_{2} \cdot{ }^{5,6}$ For this reason, we suppose it has worked in our case. Of course, these clinical observations need to be verified by more data to be confirmed. We thought of sharing our experience to encourage other colleagues to undertake the use of nHFOV in the course of bronchiolitis (rescue therapy) to try to better understand a type of ventilation still little known.

\section{Conflict of Interest}

G.M. reports nonfinancial support from null during the conduct of the study.

\section{References}

1 Groothuis JR, Simoes EA, Hemming VG; Respiratory Syncytial Virus Immune Globulin Study Group. Respiratory syncytial virus (RSV) infection in preterm infants and the protective effects of RSV immune globulin (RSVIG). Pediatrics 1995;95(04):463-467

2 Franklin D, Babl FE, Schlapbach LJ, et al. A randomized trial of high-flow oxygen therapy in infants with bronchiolitis. N Engl J Med 2018;378(12):1121-1131

3 Franklin D, Fraser JF, Schibler A. Respiratory support for infants with bronchiolitis, a narrative review of the literature. Paediatr Respir Rev 2019;30:16-24

4 De Luca D, Dell'Orto V. Non-invasive high-frequency oscillatory ventilation in neonates: review of physiology, biology and clinical data. Arch Dis Child Fetal Neonatal Ed 2016;101(06):F565-F570

5 Haidar Shehadeh AM. Non-invasive high flow oscillatory ventilation in comparison with nasal continuous positive pressure ventilation for respiratory distress syndrome, a literature review. J Matern Fetal Neonatal Med 2019:1-10

6 Bottino R, Pontiggia F, Ricci C, et al. Nasal high-frequency oscillatory ventilation and $\mathrm{CO}_{2}$ removal: a randomized controlled crossover trial. Pediatr Pulmonol 2018;53(09):1245-1251 